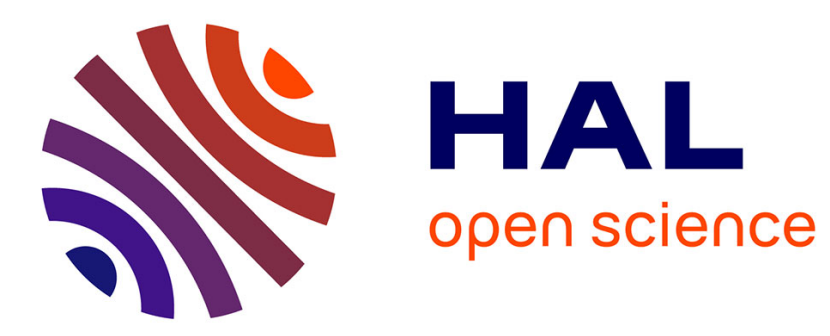

\title{
Load testing and simulation of asymmetric cable-net used for flexible rockfall protection barriers
}

\author{
Adrien Trad, Ali Limam
}

\section{To cite this version:}

Adrien Trad, Ali Limam. Load testing and simulation of asymmetric cable-net used for flexible rockfall protection barriers. European Journal of Environmental and Civil Engineering, 2021, pp.118. 10.1080/19648189.2021.2004932 . hal-03484872

\section{HAL Id: hal-03484872 \\ https://hal.science/hal-03484872}

Submitted on 21 Jan 2022

HAL is a multi-disciplinary open access archive for the deposit and dissemination of scientific research documents, whether they are published or not. The documents may come from teaching and research institutions in France or abroad, or from public or private research centers.
L'archive ouverte pluridisciplinaire HAL, est destinée au dépôt et à la diffusion de documents scientifiques de niveau recherche, publiés ou non, émanant des établissements d'enseignement et de recherche français ou étrangers, des laboratoires publics ou privés.

\section{다)(1) $(5$}

Distributed under a Creative Commons Attribution - NonCommercial| 4.0 International 


\title{
Load testing and simulation of asymmetric cable-net used for flexible rockfall protection barriers
}

\author{
Adrien Trad ${ }^{\mathrm{a}, \mathrm{b}}$ and Ali Limam ${ }^{c}$ \\ ${ }^{a}$ CESI, École d'Ingénieurs, Nanterre, France; ${ }^{b}$ Université de Lyon, INSA-Lyon, LGCIE, Villeurbanne, France; \\ 'Université de Lyon, INSA-Lyon, MATEIS CNRS UMR5510, Villeurbanne, France
}

\begin{abstract}
Flexible protection barriers are often located on the mountainsides in order to decrease the risk of rockfall. In the present study, different scales of experimental tests are considered, to gauge the behaviour and to estimate the bearing capacity of a new type of cable-nets used for these flexible barriers in case of quasi-static loads. A large experimental campaign addressing cables characterization, as well as the behaviour of the constitu-tive cells of the net, which particular shape, a water drop shape instead of the classical rings, induces asymmetric loading transfer. Finally, the net behaviour itself is characterized through appropriate tests. These tests highlighted the non-linear behaviour perceived at different scales and per-mitted to evaluate the bearing capacity of the various components. Numerical simulations using the finite element code Abaqus were also con-ducted for the different components, a group of constitutive cells with rigid or fuse clip or the whole net, to reproduce the behaviour observed experimentally.
\end{abstract}

\section{KEYWORDS}

Rockfall protection; cable-net; non-linear behaviour; energy dissipation; finite elements simulation

\section{Introduction}

Mountain areas are defined by the slopes of the valleys more or less abrupt. Under the effect of various forces (earthquake, gravity, water, freeze-thaw processes, chemical degradation, human actions ...) it may happen, that unstable rocks fall causing landslides below. The reduction of the risk due to rockfall and landslides is obtained at different levels. The strategy called 'active' is intended to prevent the risk of a landslide affecting the stability of rock mass by a reinforcement using a retained net (Bertolo et al., 2009; Sasiharan et al., 2006) or other technologies. The design of this structure has largely been based on empirical guidelines as followed in North America (Sasiharan et al., 2006). On the contrary, the so-called 'passive' is intended to catch the rockfalls and landslide with flexible barriers that operates on various parameters (absorbed energy, velocity, mass, height of the impact ...), (Cazzani et al., 2002; Hearn et al., 1995; Moon et al., 2014; Nicot et al, 2001; Peila et al., 1998; Zhiwei et al., 2018). In this case, the design was based on calculations like the recommendations of the French standard NF P95-308 (1996). Since 2001, new guidelines based on the experimental validation of rockfall protection kits have been published (EOTA, 2018; ETAG 27, 2008; Gerber, 2001).

The rockfall protection barrier is composed mainly by the net and the energy dissipators (Trad et al., 2010) as shown in Figure 1. Different types of metallic nets are usually used (Bertolo et al., 2009; CastroFresno et al., 2008; Nicot et al, 2001).

Rockfall protection barriers are usually experimentally tested to characterize their limit impacting energy associated to the barrier failure (Arndt et al., 2009; Bertolo et al., 2009; Grassl et al., 2002; Hearn 
et al., 1995; Peila et al., 1998). The last decades numerical simulations methods are increasingly used for barrier performance prediction (Anderheggen et al., 2002; Bertrand et al., 2012; Cantarelli et al., 2008; Cazzani et al., 2002; Volkwein, 2005).

More recent studies (Boulaud, 2020; Dugelas, 2020; Coulibaly et al., 2019; Coulibaly, 2017) conducted within the frame of the French National project C2ROP give experimental and numerical research works on a prototype rockfall barrier. In Dugelas et al. (2019), the capacities and limitations of DEM modelling approaches for the assessment of the response of rockfall protection barrier were investigated. The chosen methodology consists in modelling and calibrating separately each element of the protection barrier, and assembling them together to get the full barrier model which is finally validated in comparison with the dynamic experimental full scale tests results without any back analysis. This demonstrates the robustness of the adopted simulation method. Only little deviations from the experimental results are observed and they are attributed to the slight differences between the real and the modelled structure. It was concluded that the DEM approach is suitable for modelling flexible barriers impact. Other research contributions focus on FEM approach models, such as the beam model proposed by Escallón et al. (2014), or truss elements, namely, $1 \mathrm{D}$ elements without flexural rigidity used for the cable net meshing proposed by Castanon-Jano et al. (2018).

Yu et al. (2019) investigate the nonlinear mechanical behaviour of metallic wire-ring net. Quasi-static tests, including tensile tests on steel wires and one-ring specimens, and puncturing tests on net specimens were conducted. Their developed model based on FEM approach, shows an equivalence between the numerical and actual wire rings in terms of bending and tensile strength, and the different inherent nonlinearities as contact with sliding friction and the flattening effect occurrence near the contact zones between cables, and even rupture behaviour were well reproduced.

The majority of metallic nets are made of cells in the form of perfect rings. Here a particular rockfall wire net was studied, instead of the classical rings the constitutive cells have a water drop shape. The circular shape of the rings does not contribute to the transmission of forces in a desired direction which is the case for this particular asymmetric rockfall net. This article illustrates the experimental test procedure and results of different components of the flexible rockfall net. Numerical modelling, conducted with Abaqus package helps to understand and predict the behaviour of the elements here studied.

\section{Presentation of the studied cable-net}

The net has a water drop shape and is connected by clips (Figure 1). Then the specificity of the net is to have an asymmetric geometry and then an orthotropic behaviour as will be showed latter. Then the impact force can be oriented and distributed over a wider area reducing the anchors forces in the vicinity of the impact zone. Two types of clips are developed. The rigid clips with an ultimate strength of $2 / 3$ of the cable strength and the fuse clips with an ultimate strength of $1 / 3$ of the cable strength (Figure 1). When a clip breaks, the associated net cell expands and provides an additional displacement and stress redistribution. This displacement increases the energy absorbed by the net and decreases the impact force and then the forces transmitted to the anchors. Even if all the fuse clips break, the net remains whole (Figure 2) and load diffusion to the boundaries works thanks to the cable continuity.

Fuse clips are adequate for low energy barriers $(<500 \mathrm{~kJ})$ where the energy dissipation is largely provided by the net itself. Rigid clips are more suitable for high energy barriers ( $>1000 \mathrm{~kJ}$ ) where the energy dissipation is based mainly on the energy dissipator devices.

In this article, a multi scale analysis is conducted. All the components of the net such as clips, cable and cells are studied separately trough experimental tests, then a reduced model of the net was experimentally characterized. The tests are conducted on geometries and configurations of simplified loads, but sufficiently representative of the behaviour observed in situ. Finite element model developed using the ABAQUS code permits to fit all the physical parameters and quite good agreements with experimental tests are noticed.

\section{Characterization of the cable-net components}

\subsection{The clips}

The behaviour of the clips was characterised by direct tensile test with a device simulating the cell geometry (Figure 3). 


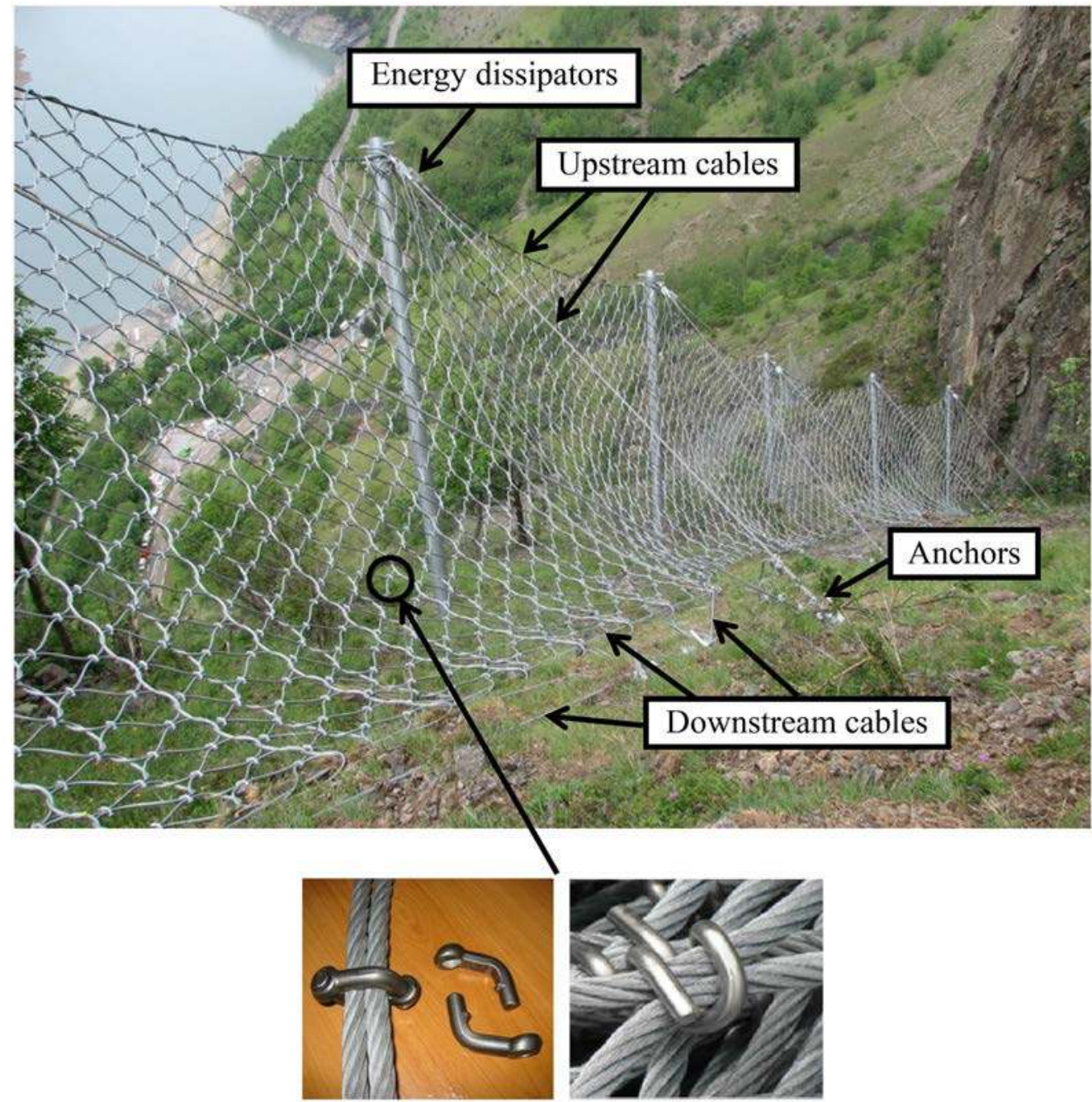

Figure 1. View of the flexible rockfall barrier showing the different components and two types of clips (left: Rigid clip, right: Fuse clip).

The data collected is the displacement, the force and images of a CCD (Charge-Coupled Device) camera. This camera, allowed visualizing the geometry evolution of the clip according to the applied force and detecting the important moments of the behaviour like beginning of the clip opening, complete opening and final failure. These photos show that the linear limit of the behaviour matches the initial opening of the clip. The behaviour of a fuse clip used for low energy barriers is shown in Figure 4.

The loading of the net induces a variation of the cell components shape, the angle of cell opening varies, which can cause a change in the clip's behaviour. For this, clips characterization tests with different angles were made. The geometry was reproduced perfectly with particular respect to the angle of the cell opening; it is $130^{\circ}$ for the initial geometry and $110^{\circ}$ for the deformed one just before the final rupture of the net (Figure 5).

Tests on clips with opening angles of $110^{\circ}$ and $130^{\circ}$ were achieved. The behaviour obtained with these two angles is very similar. Another experiment with an opening angle of $10^{\circ}$ was done, and the result confirms the negligible effect of this parameter. Same results are noticed for rigid clips, in all configurations, the opening angle characterizing the cell shape have a small effect. The curves representing the tensile behaviour of fuse clip with angles of $10^{\circ}, 110^{\circ}$, and $130^{\circ}$ are shown also in Figure 4 .

The behaviour of the clamp is then not influenced by its opening angle. Therefore, the assumption of modelling the clip by a truss element with two hinged ends seems justified. 


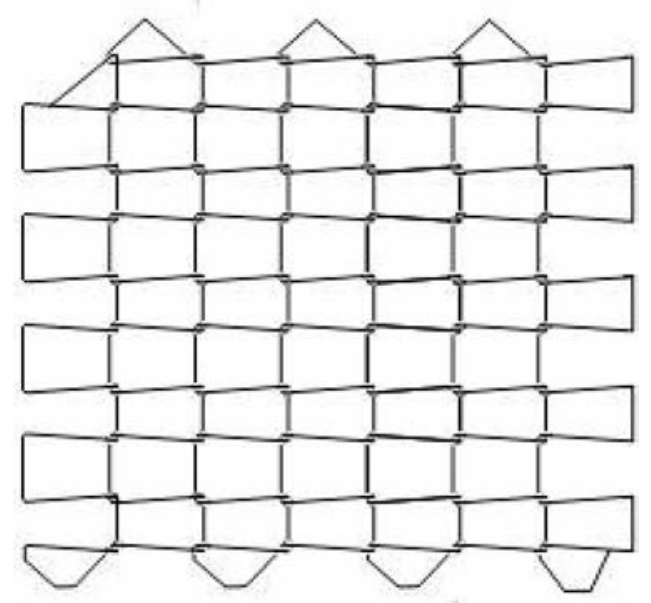

Figure 2. Shape of the net after all clips breaking.

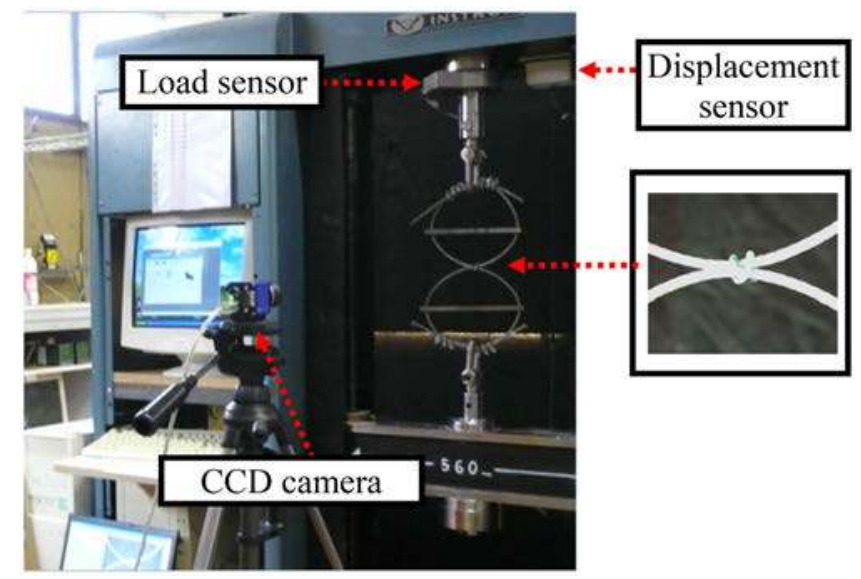

Figure 3. Description of the tensile test on the clips.

The rigid clips are also characterized. A comparison between the behaviour of a rigid and a fuse clip is shown in Figure 6 . The load bearing capacity of rigid clip is 2,3 higher and maximal displacement at failure onset is four times lower. Fusible clips are attended to be used for low energy impact barrier.

\subsection{The cable by tensile test}

An optical method of measurement was used to characterize the cables in tension. The cable is fixed on the two ends of the machine where the lower end goes down and generates the tensile force. Two marks are placed on the cable and a CDD camera measures in continuous the number of pixels between these two marks from the beginning till the failure. Using this method, slippage at the cable boundaries does not have any effect on the measures. The force sensor is synchronized with the CCD camera in order to measure the force and the displacement at the same time. The cable diameters used for a rockfall barrier depends its energy classes. Here only the behaviour for the $\phi=6 \mathrm{~mm}$ diameter and $\phi=8 \mathrm{~mm}$ diameter cables are presented (Figure 7). The cables have the same global behaviour, first a linear part, followed by a short nonlinear part just before the failure. This last part corresponds to the yielding and the damage due to the progressive failure of the cable wires. 


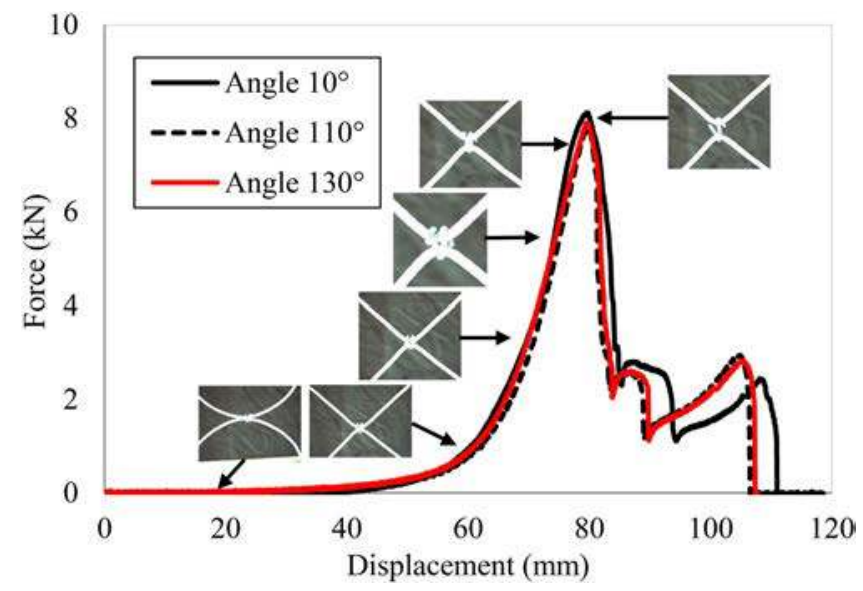

Figure 4. Behavior of fuse clips with different opening angles.
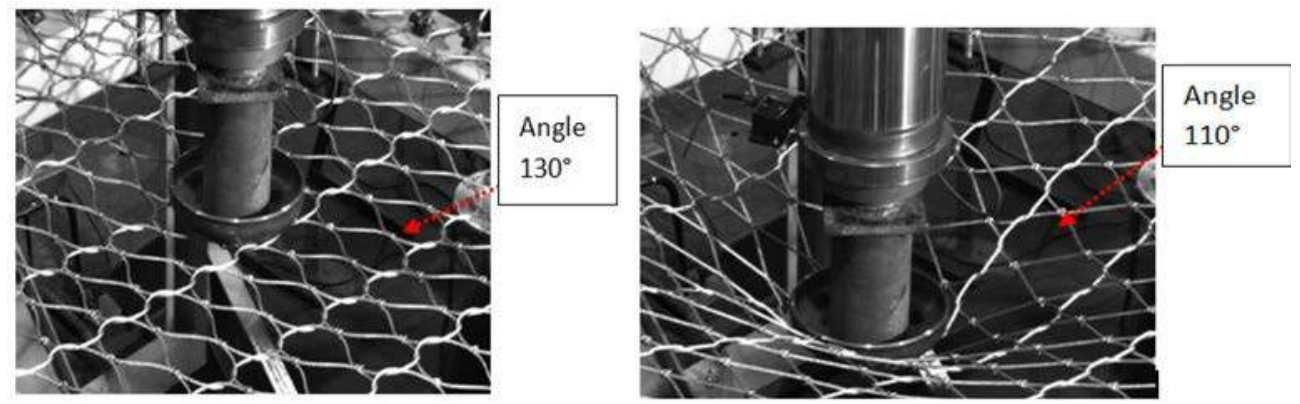

Figure 5. Opening angles of the mesh for the non-deformed and the deformed geometry of the net.

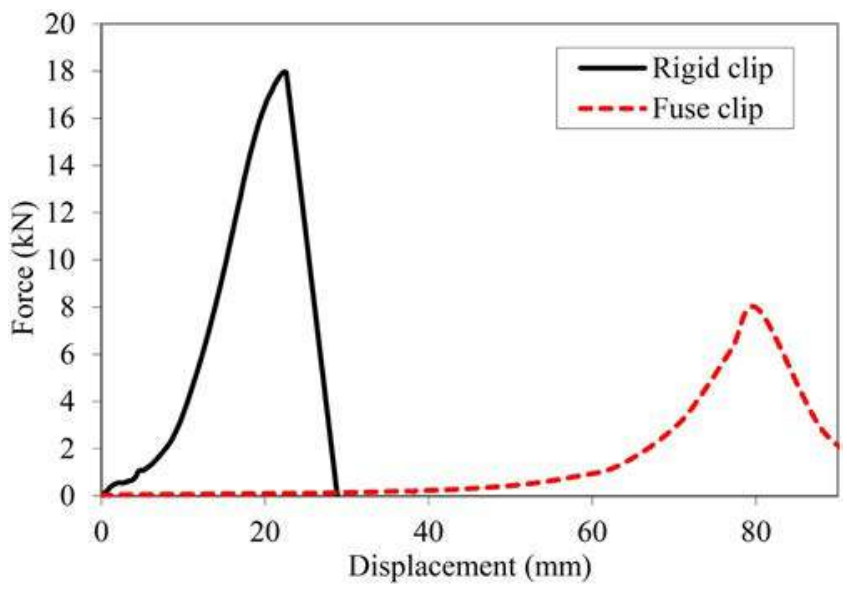

Figure 6. Behaviour of the rigid and fuse clips.

\subsection{The cable by bending test}

A cable with a length $L$ is hinged to a rigid frame and submitted to an initial tensile load $(P)$, then an orthogonal load (T) is applied at the mid-length and is gradually increased (see Figure 8). The goal is to study the influence of the cable pre-tension $\mathrm{P}$ on its deformability under bending load ' $T$ ' applied perpendicularly to the cable. This kind of tests allows to gauge membrane-bending or tensile-bending interaction which is a characteristic of cable behaviour of a rockfall net. 


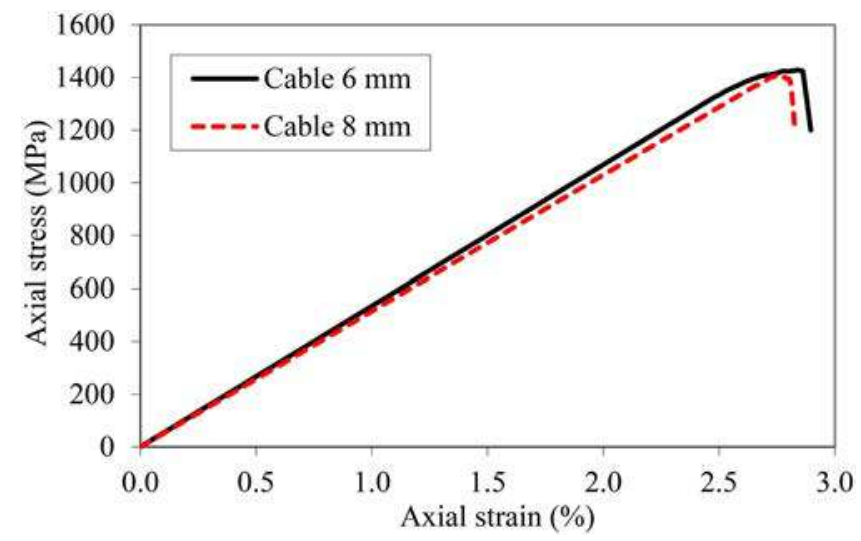

Figure 7. Cable mechanical behaviour under tensile load $-\phi=6$ and $\phi=8 \mathrm{~mm}$ cables.

Several tests are conducted where the initial tensile load and the cable section are the parameters. Test results for the $8 \mathrm{~mm}$ cable pre-tensioned at $1 \mathrm{kN}, 5 \mathrm{kN}, 10 \mathrm{kN}$ and $15 \mathrm{kN}$ are shown in Figure 9. It's observed that the bending stiffness depends on the pre-tension load level. The non-linearity of the behaviour is more accentuated under low levels of pre-tension.

\section{Characterization of the constitutive cells}

\subsection{Tensile test on cells with rigid clips}

A representative part of the net constituted of 5 cells (Figure 10) was submitted to a tension load in order to characterize its behaviour and to validate later a numerical model at this scale.

The force displacement behaviour and the geometry evolution were recorded during these tests. Two cable configurations $\phi=12 \mathrm{~mm}$ and $\phi=16 \mathrm{~mm}$ cable diameters were tested. Figure 10 shows the result obtained for the $\phi=16 \mathrm{~mm}$ cable net with rigid clips. As for the configuration $\phi=12 \mathrm{~mm}$, the observed global behaviour is similar, characterized with 3 different stages:

- Stage A: geometrical nonlinear behaviour corresponding to large displacements (till $\sim 90 \mathrm{~mm}$ ) with very low level of loading. This is due to the low bending stiffness of the cable. At the end of this stage, the cells geometry becomes like diamonds instead of water drop, a large variation of the cell shape was then observed during this phase.

- Stage B (till $\sim 118 \mathrm{~mm}$ ): the cables are stressed; the cells have a diamond shape and doesn't change anymore during this phase; the global behaviour is almost linear.

- Stage C: a short nonlinear zone is observed before the failure corresponding to the yielding, damage and the failure of the cable wires.

\subsection{Tensile test on cells with fuse clips}

Energy can be resumed by the force times the displacement. When the structure overall displacement is increased by the use of fuse clips, the energy dissipated becomes larger. As mentioned previously, fuse clips have a failure load around $1 / 3$ of the cable failure load. This induces breaking of the clips at early time of loading, reduces the impact force and increases the energy dissipated by the net. Each time a clip fails, force is redistributed to the narrow cells and associated clips, and this process will progress until the failure of all the clips. At the end, the net is loaded without clips and has a linear behaviour till the failure of the cable (Figure 11).

To highlight the effect of the use of fuse clips in terms of energy dissipation, a comparison was made between constitutive cells with rigid and fuse clips. The gain of energy dissipation was around $270 \%$ (Figure 12). 

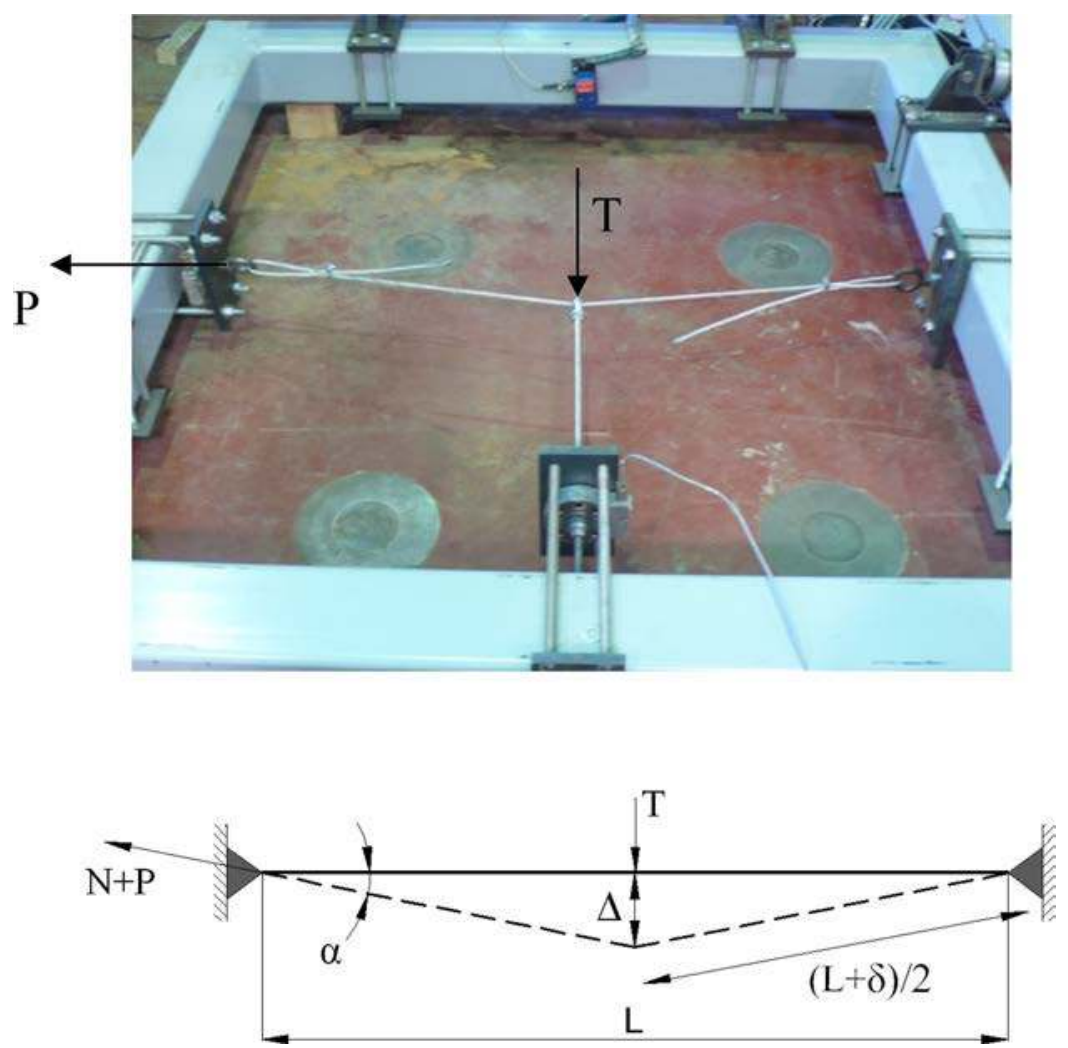

Figure 8. View of the bending test on cables and the corresponding model.

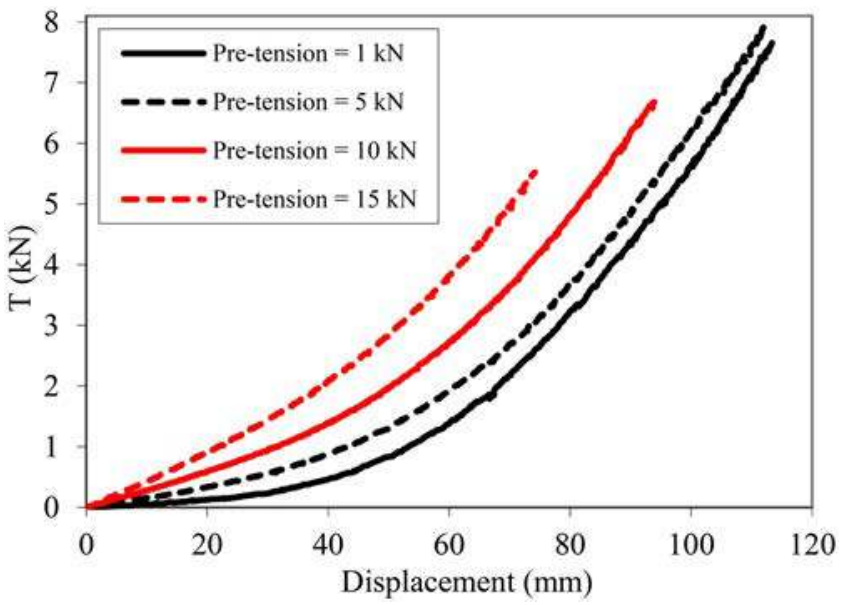

Figure 9. Behaviour of the $8 \mathrm{~mm}$ cable with different levels of lateral pre-tension.

\section{Characterization of the cable-net}

\subsection{Punching test: rigid clips net}

A specific bench test was developed to simulate the impact of a rock on the net but in a quasi-static mode. The net is made of a half scale geometry (net with cables of $6 \mathrm{~mm}$ and $8 \mathrm{~mm}$ to simulate respectively the case of $12 \mathrm{~mm}$ and $16 \mathrm{~mm})$, it is of a square shape $(2 \mathrm{~m} \times 2 \mathrm{~m})$ and is attached to a rigid framework through rods with intermediate hinges. This latter permit to consider the net as perfectly hinge 


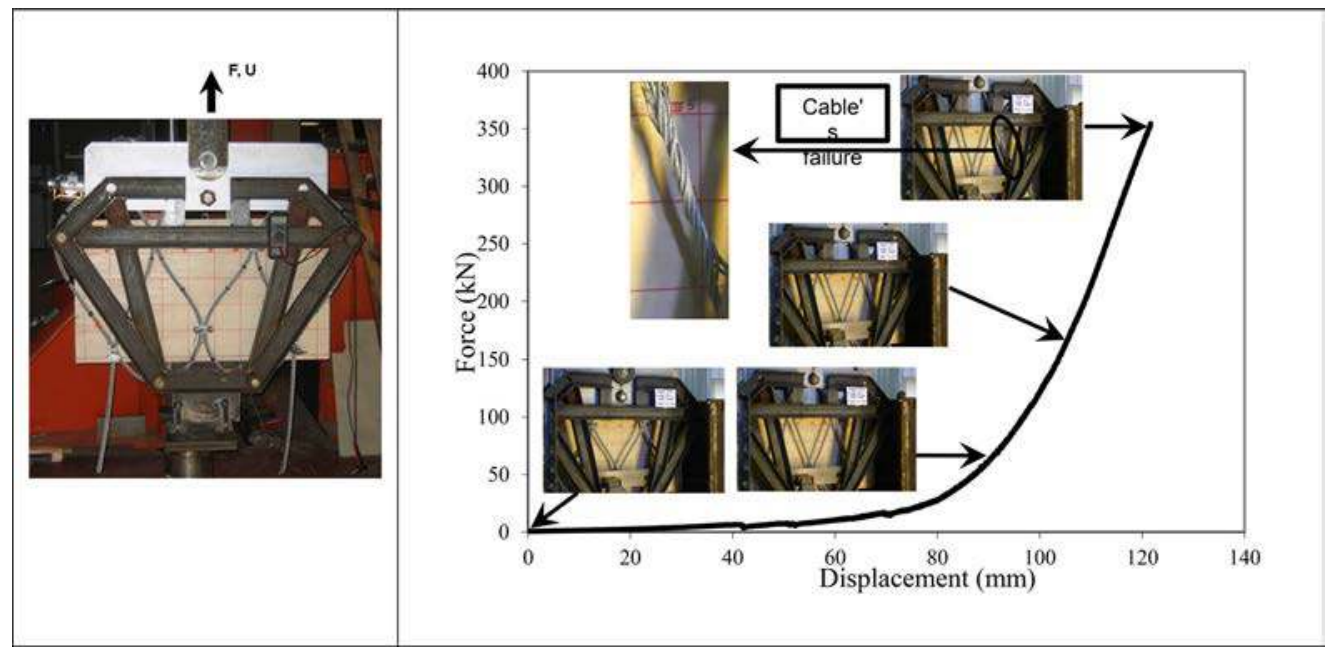

Figure 10. View of the bench test on cells and the corresponding behaviour for a $\phi=16 \mathrm{~mm}$ cable diameter with rigid clips.

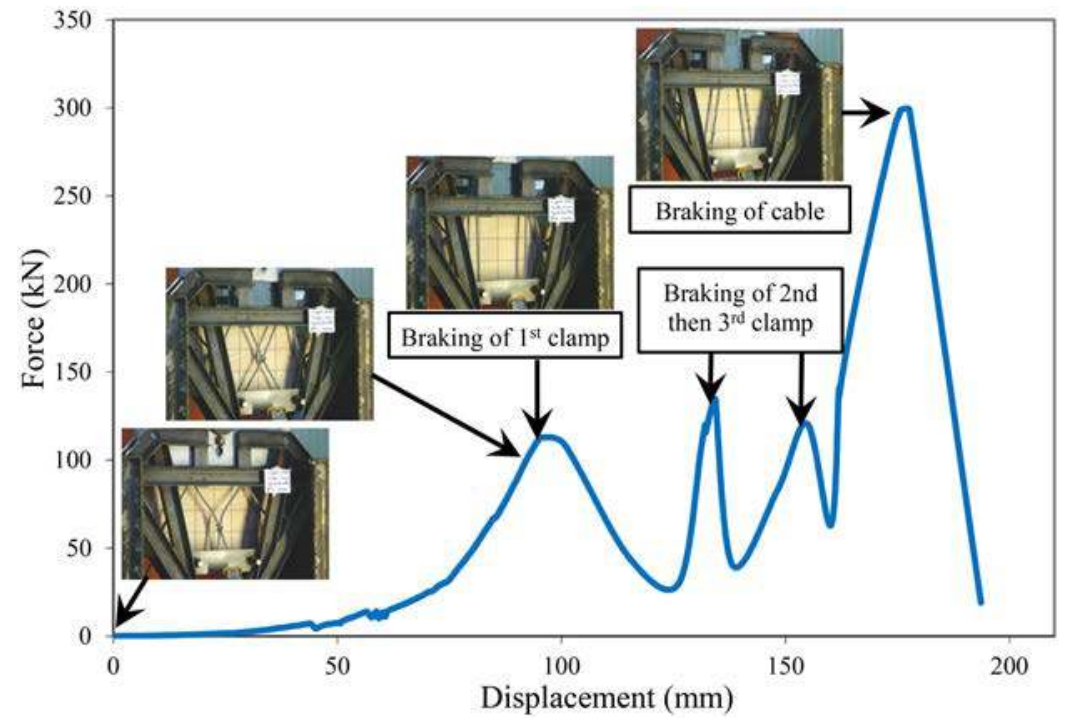

Figure 11. Behaviour of the mesh under tension $-\phi=12 \mathrm{~mm}$ cable diameter with fuse clips.

connected at its four sides (Figure 13). The objectives are to evaluate the net behaviour in terms of ultimate load, lateral transmission of load and energy dissipation.

The net is loaded by a vertical hydraulic jack installed at the middle of the net. The jack is equipped at its end by a metal cap having a diameter proportional to the net area and simulating the impacting block. Force and displacement sensors are installed in the jack in addition of a CCD camera. All sensors are synchronised in order to make a correlation between the measurements and the photos taken by the camera. The behaviour of the net is characterised by the force-displacement curve shown in Figure 14 .

The behaviour of the net under punching is similar to the behaviour of the mesh under tension test described previously. A first stage corresponds to large displacement for very low load level. Once the net cable becomes straight (no bending), the net force increases significantly in a quasi-linear behaviour phase. At the end, a short zone of nonlinearity precedes the failure. This nonlinearity is attributed to the material yielding and to the failure of the cable wires. The failure of the net arises by the failure of the cable in the vicinity of the loading zone.

The net edges are instrumented with load cells in order to quantify the orthotropic behaviour due to the water drop-shaped geometry, see Figure 13. Results show that the net supports, according to the 


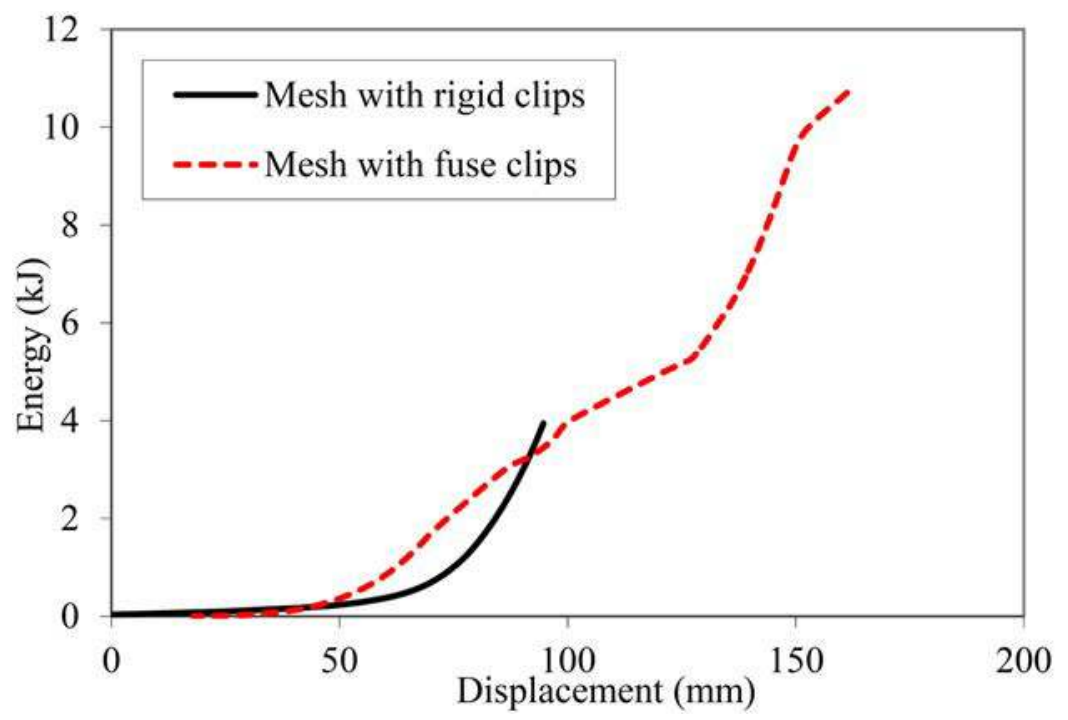

Figure 12. Energy dissipated by fuse clips net in comparison with rigid clips net.

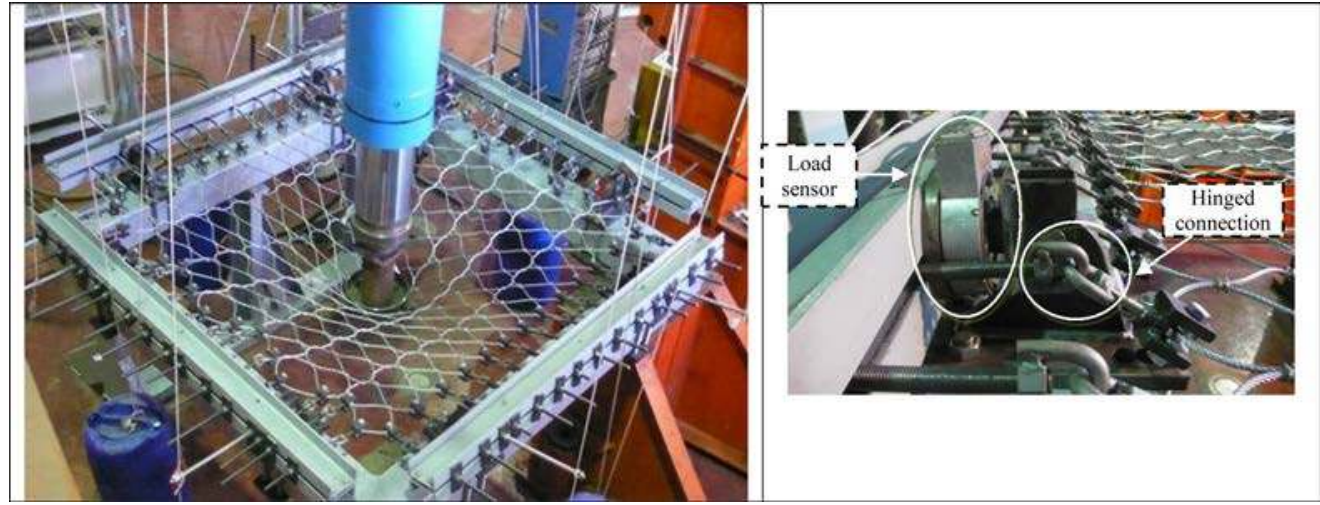

Figure 13. View of the test bench for the net under punching and zoom on the instrumentation at the boundary.

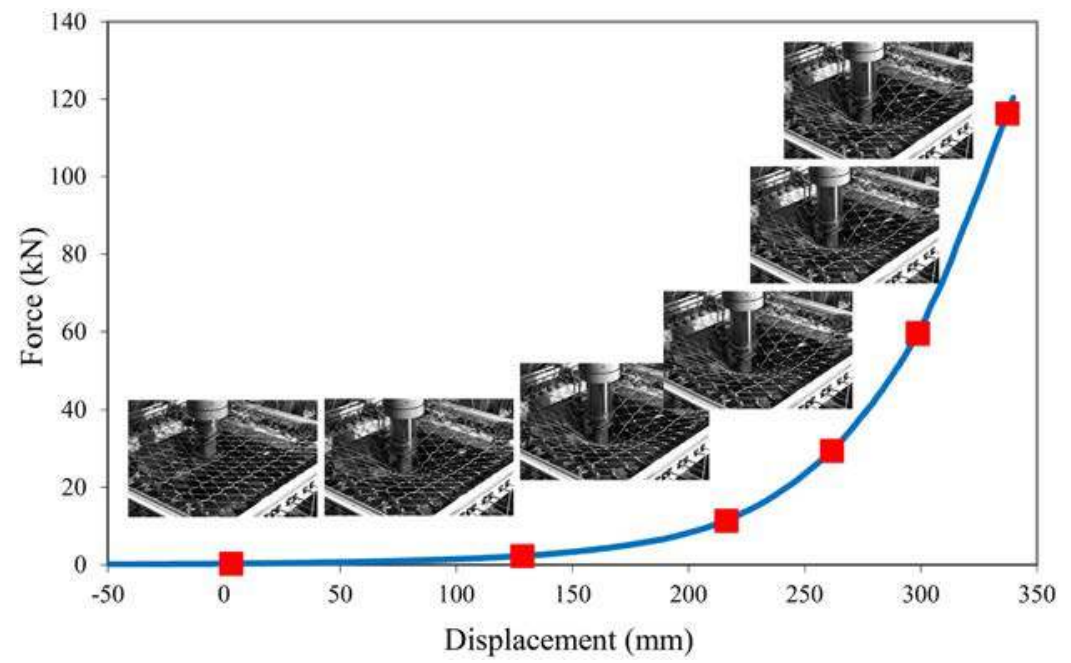

Figure 14. Behaviour of the net under punching $-\phi=6 \mathrm{~mm}$ net with rigid clips. 


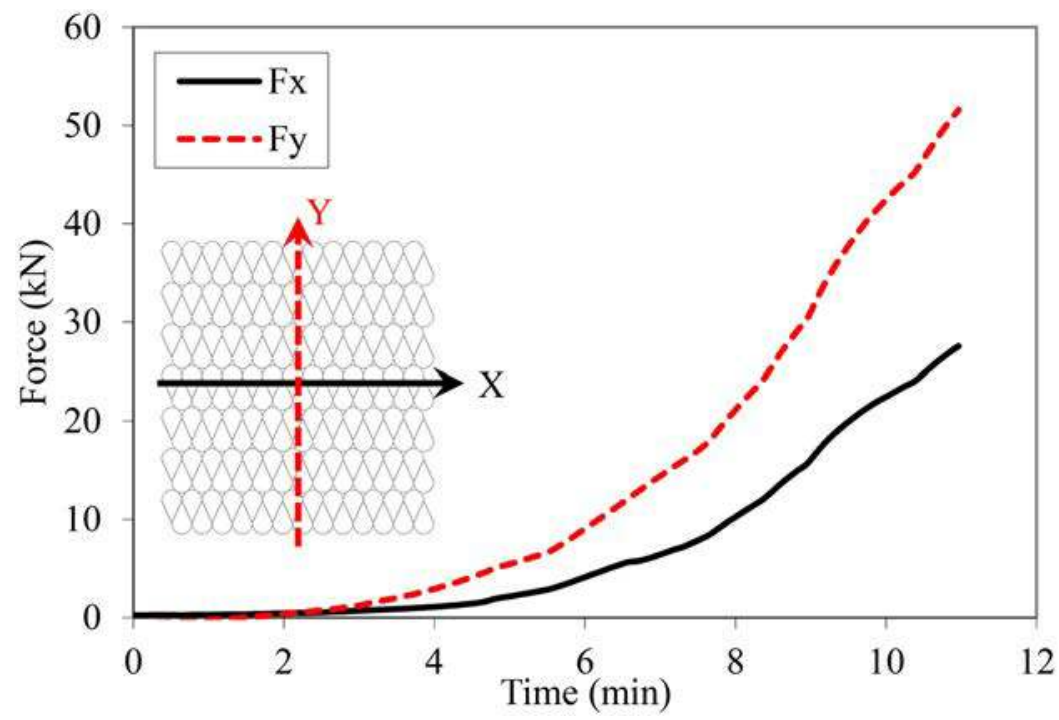

Figure 15. Reactions at the net's supports in the two main directions.

main axis of the cell, a resulting membrane force of 60 to $80 \%$ higher than the force taken orthogonally to this axis (Figure 15). This property permits to reduce the forces transmitted to the upstream and downstream cables of the barrier in the vicinity of the impact region and to transmit higher part of forces further in the net longitudinal direction.

The effect of the surface of the loaded area, which represents the size of the rock, was also studied. A test campaign is conducted to assess the effects of this parameter. For these tests, various diameters of metallic caps are fixed on the head of the jack.

Tests show that the rigidity and the bearing capacity increase when the loaded area increase. With the decrease of the surface, the effect of localized pocket is excited and this singularity induces stress gradients highly localized on the cables, which explains the premature failures. These phenomena are even more remarkable when the cables' diameter is smaller. These effects are highlighted in Figure 16.

\subsection{Punching test: fuse clips net}

Fuse clips fail for a load level around $1 / 3$ of the cable ultimate load. This phenomenon is clearly shown on the net behaviour curve (Figure 17). A first geometrical nonlinear stage is followed by the clip's progressive failure. Each time a clip fails, the forces are redistributed to the other clips till the failure of all of them. At the end, the net cable is loaded till its failure.

The clips failures are accompanied by supplementary net displacement which increases the dissipated energy, obtained latter by the integration of the load-displacement plot. Figure 18 shows the energy dissipated by the net in case of rigid or fuse clips. An increase of the dissipated energy of around $280 \%$ was noticed in case of fuse clips compared to the rigid clips case. This gain of energy is similar to the one realized during the constitutive cell's tests.

\section{Modelling}

\subsection{Analytical and numerical simulations of the cable behaviours}

The cable tests presented above (Figure 8) allows to validate the FE numerical simulation and the analytical model at the scale of the cable, when both membrane and bending loading are applied. As demonstrated in Appendix A, a polynomial equation of the third degree represents the analytical behaviour of a pre-stressed cable of a length $\mathrm{L}$, under lateral load $\mathrm{P}$ and submitted to an orthogonal load $\mathrm{T}$. It shows the non-linear relation between the deflection and the prestress level. 


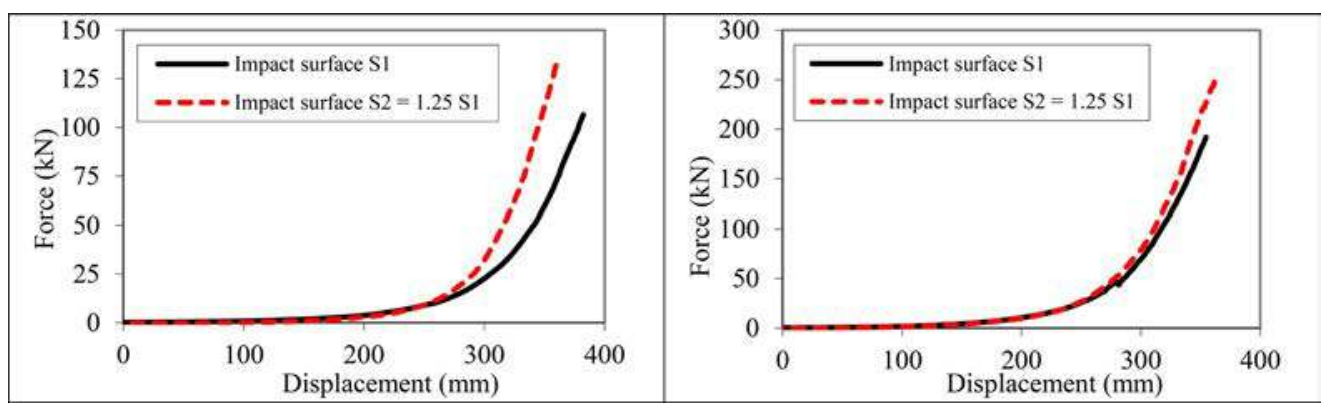

Figure 16. Impact surface influence - left) $\phi=6 \mathrm{~mm}$ cable diameter, right) $\phi=8 \mathrm{~mm}$ cable diameter.

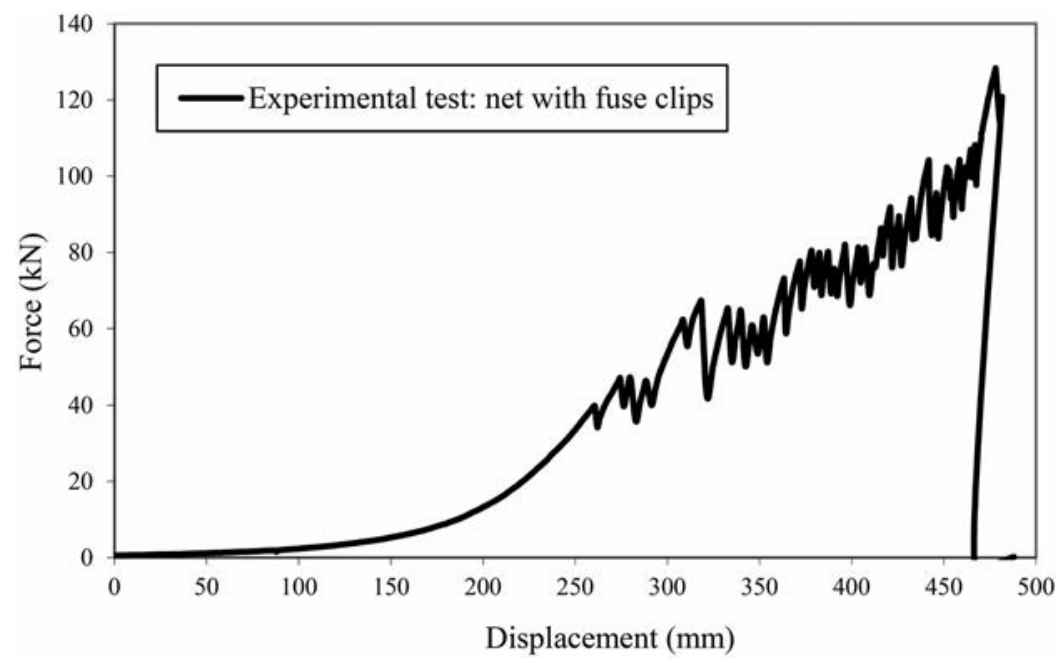

Figure 17. Behaviour of the net under punching $-\phi=6 \mathrm{~mm}$ net with fuse clips.

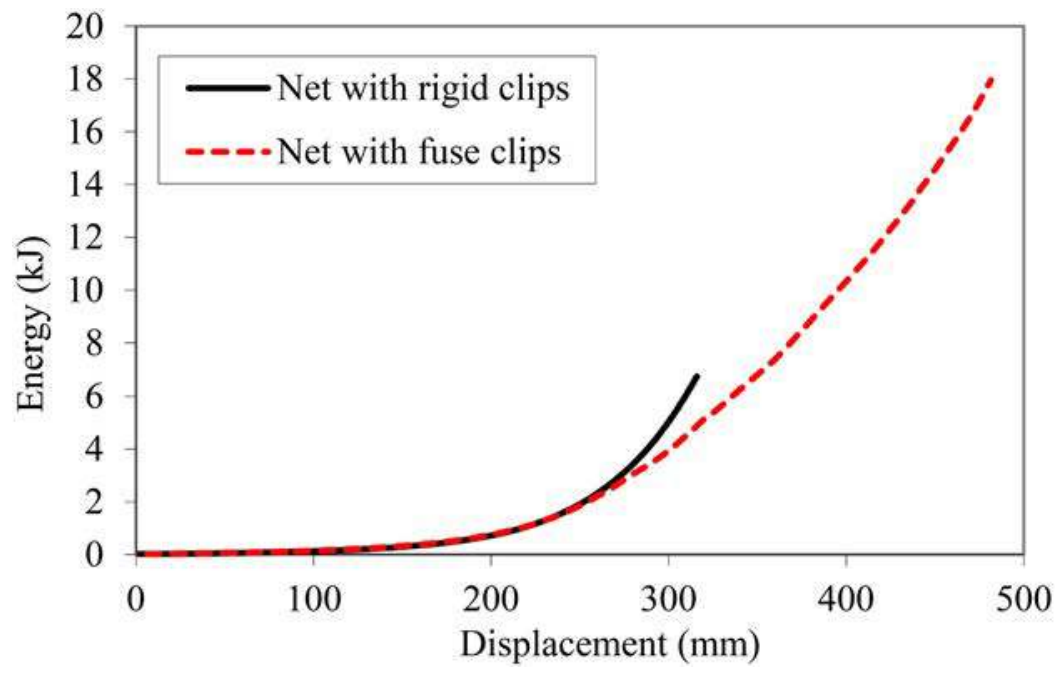

Figure 18. Energy dissipated by the net with rigid or fuse clips. 


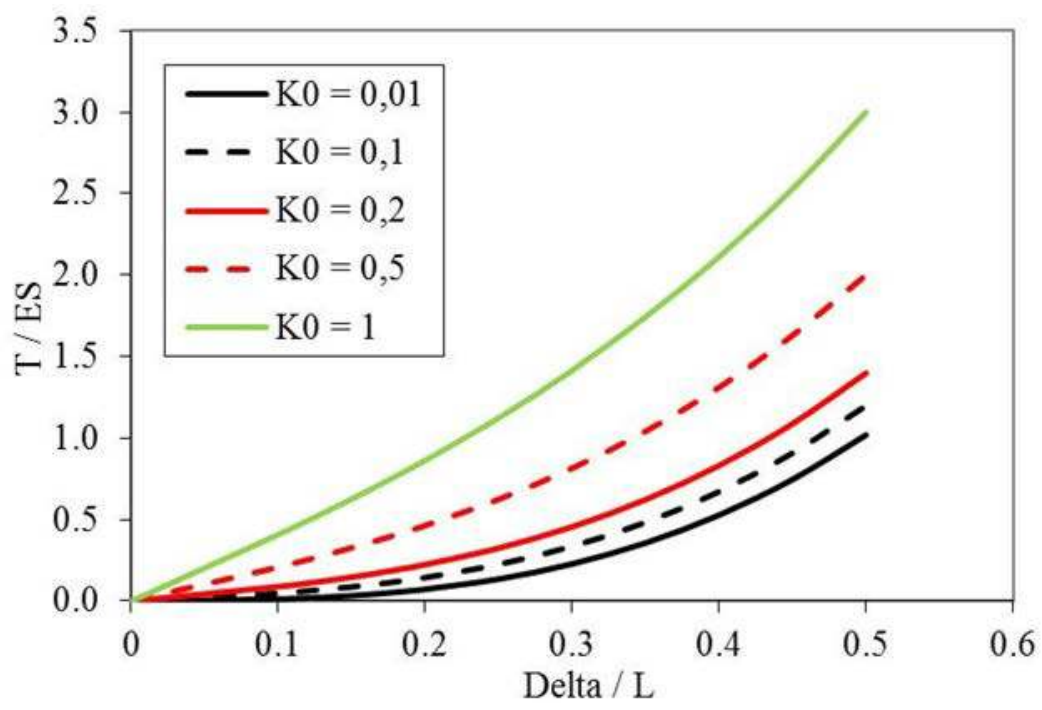

Figure 19. Non-linear behaviour of the cable.

$$
8\left(\frac{\Delta}{L}\right)^{3}+4 \frac{P}{E S} \frac{\Delta}{L}=\frac{T}{E S}
$$

$\Delta$ and $\mathrm{L}$ are defined in Figure $8 . \mathrm{E}$ and $\mathrm{S}$ are the modulus of elasticity and the cross section of the cable respectively.

$$
\text { Consider: }=\frac{\Delta}{L}, Y=\frac{T}{E S} \text { and } K_{0}=\frac{P}{E S} \text {, the equation becomes: } 8 X^{3}+4 K_{0} X=Y
$$

Figure 19 shows graphically the relation between $Y(T / E S)$ function of $X(\Delta / L)$. It is observed that the behaviour is non-linear and that the bending stiffness depend on the pretension level.

A numerical FE simulation was also developed using the beam element of Abaqus code in its implicit version. Nonlinear incremental calculation taken into account large displacement are considered. The cable has a low bending stiffness. Its behaviour is between a truss element with no bending stiffness and a beam element with a full beam bending stiffness. Different trials were made in order to find the adequate reduction of the moment of inertia I associated to the section definition and mesh convergence check. A value of 0.2 I was found to be adequate; the initial bending rigidity was then affected by the same coefficient. It produced good matching with the experimental and analytical results as shown in Figure 20. This type of element will be called 'degraded beam' in this text.

The maximal remained difference between the curves is less than $10 \%$. This difference can be attributed to the friction between the wires of the cable which is not considered in the simplified analytical and numerical models.

\subsection{Numerical simulations of the tensile test on cells with rigid clips}

The difficulty in modelling structures made of cables lies in the strongly non-linear behaviour corresponding to the stage A described previously. This part of the curve traduces first the bending rigidity of the cable (with its specific cell shape) and the transition phase where both membrane and bending rigidity are involved. During this phase a deep change in the constitutive cell shape was noticed, geometrical non linearities (large displacement and rotations) have to be considered in the model. This means that initial stiffness matrix of the model will be updated after each step of calculation to take into account the new geometry of the net. For the meshing (Figure 21) 126 degraded beam elements (with 0,2 I as moment of inertia) are used for each water drop cell element, then, the total number of elements used for a group of cells or for the net depends the cells number. Tests of the mesh shown in this paragraph were used in order to calibrate the properties of the model in terms of size of the element (convergence) and inertia reduction coefficient. The initial and deformed shapes of the model are shown in Figure 22. 


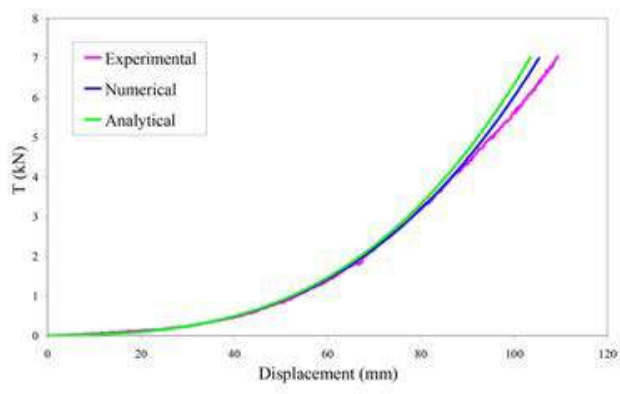

(a) Pre-tension $=1 \mathrm{kN}$

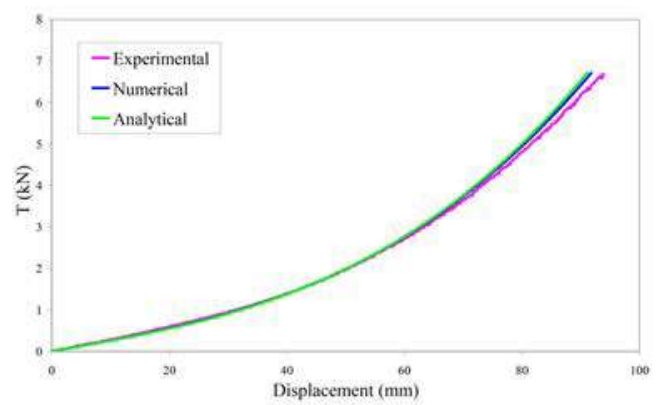

(c) Pre-tension $=10 \mathrm{kN}$

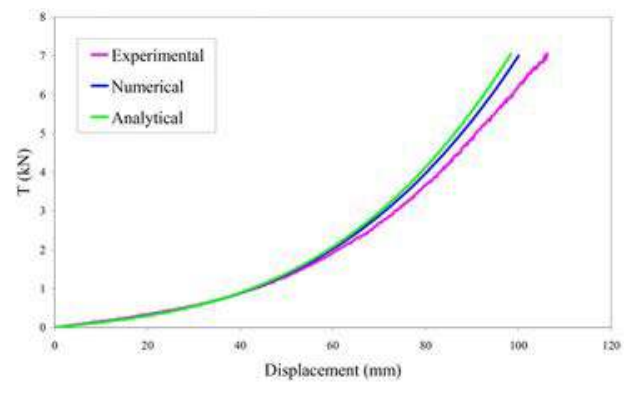

(b) Pre-tension $=5 \mathrm{kN}$

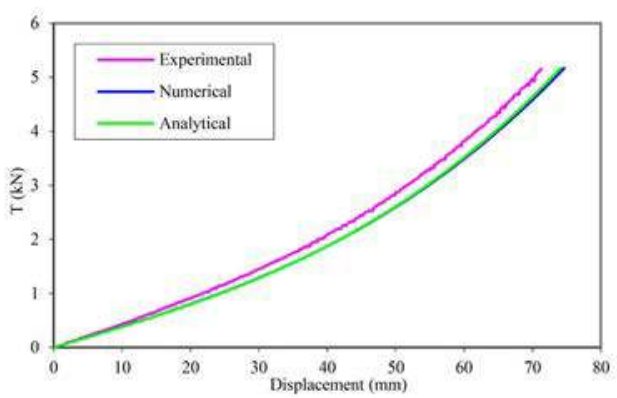

(d) Pre-tension $=15 \mathrm{kN}$

Figure 20. Comparison between the experimental, numerical and analytical results for different levels of pre-tension load. (a) Pretension $=1 \mathrm{kN}$, (b) Pre-tension $=5 \mathrm{kN}$, (c) Pre-tension $=10 \mathrm{kN}$, (d) Pre-tension $=15 \mathrm{kN}$.

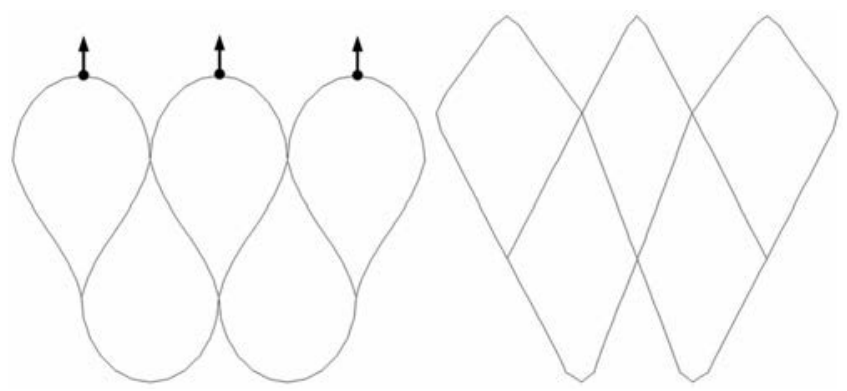

Figure 21. Representative model of the mesh - Initial shape (left) and deformed shape (right).

A reduction of the beam inertia by $80 \%$ (reduction coefficient of 0.2 ) was necessary in order to fit the experimental behaviour curve. Figure 22 shows a perfect matching between the numerical and experimental curves and validates the assumption of degraded beam elements.

\subsection{Numerical simulations of the tensile test on cells with fuse clips}

The simulation of this test took into account a degraded beam element for the cables as calibrated previously. The fuses clips are simulated by truss elements with an elasto-plastic behaviour corresponding to their behaviour characterised experimentally. Due to the non-smooth variations observed on the experimental load deflection (Figure 23), the Abaqus explicit analysis was carried out to face the abrupt nonlinearities traducing geometrical and material nonlinearities. 


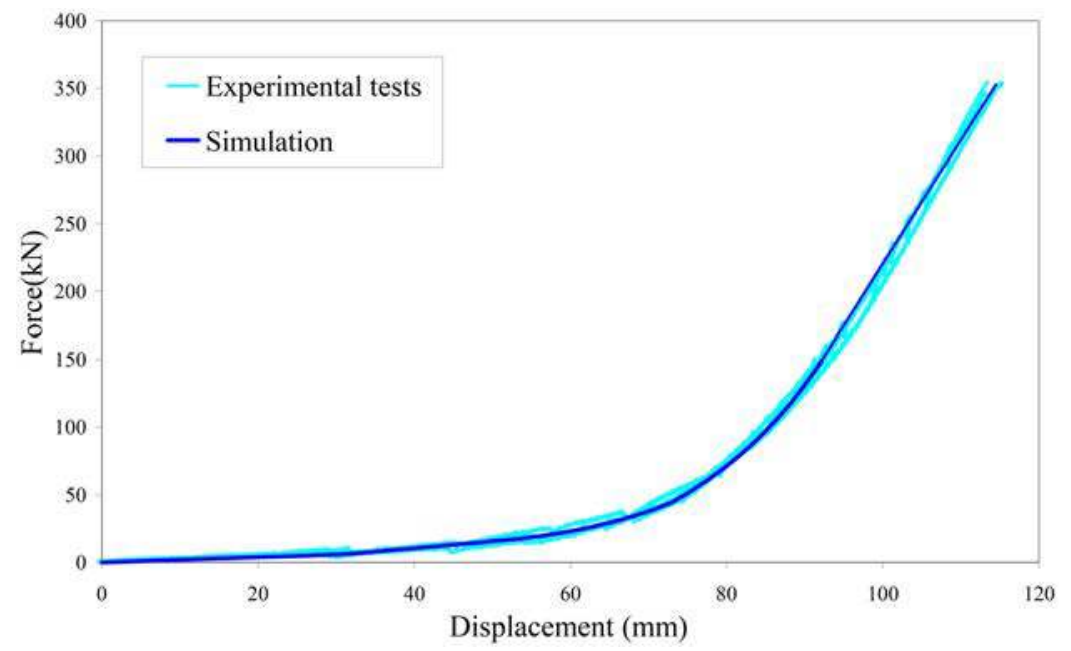

Figure 22. Numerical behaviour of the net in comparison with the test results.

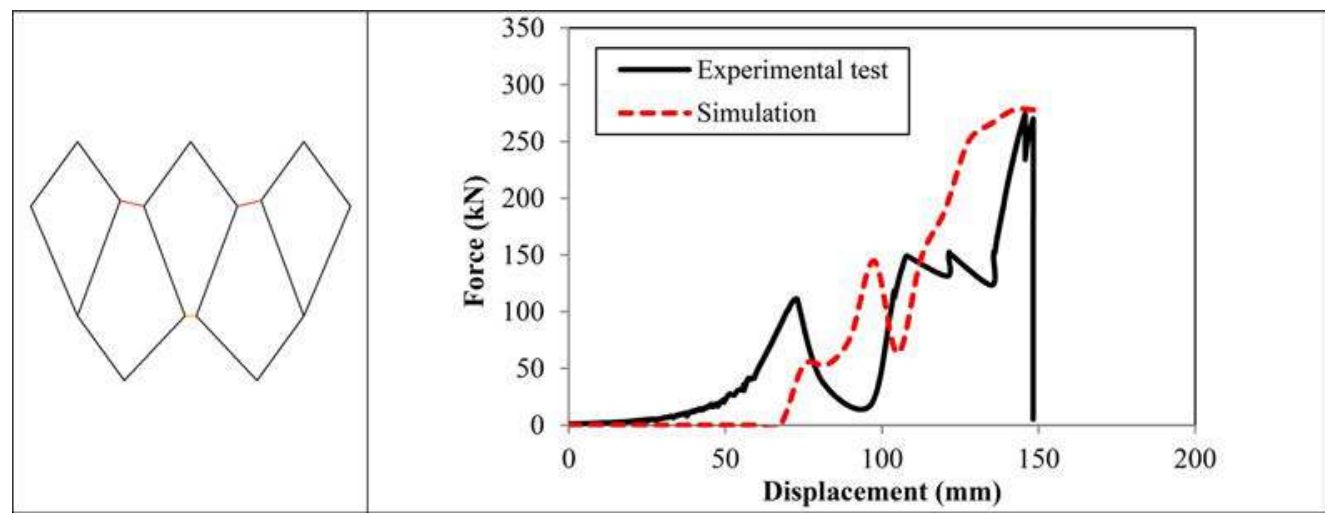

Figure 23. Test on the mesh with fuse clips- left) view of the deformed shape, right) comparison of the behaviour between the test and the simulation.

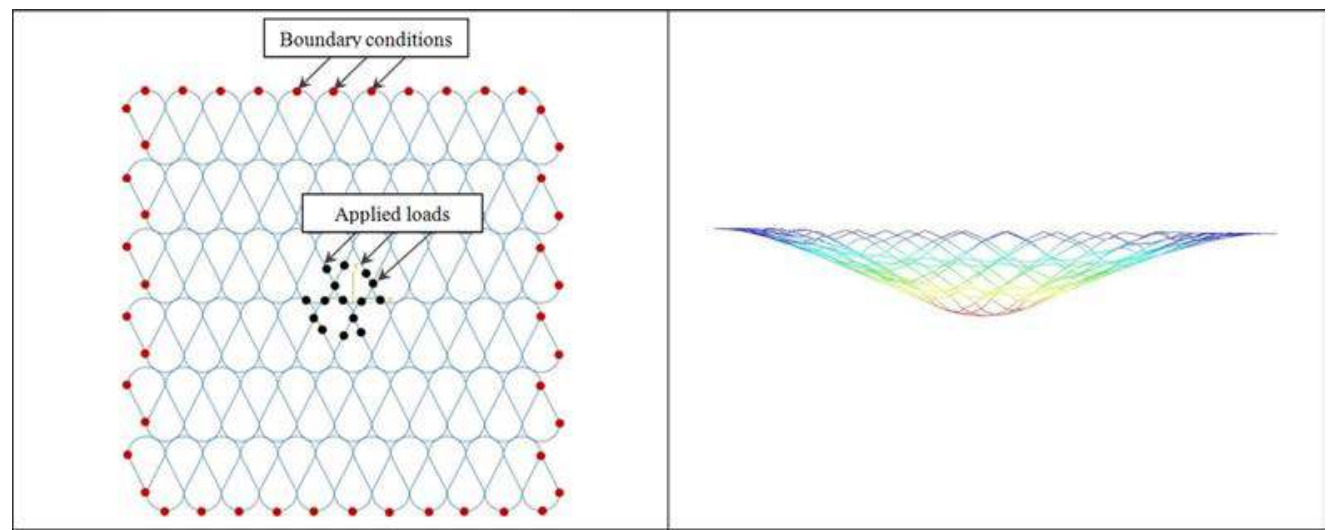

Figure 24. Numerical model of the net punching test - left) view of the loading zone and the supports, right) view of the deformed shape.

The behaviour at the beginning is similar to the stage A behaviour of a net with rigid clip till the failure of the central clip. This failure induces a distention of the cable. The displacement increases with low 


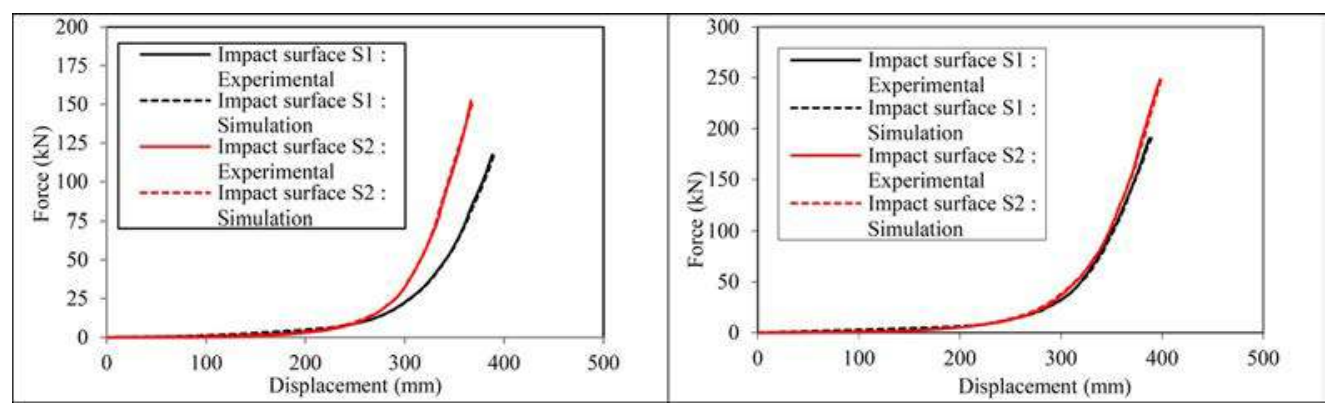

Figure 25. Comparison between the experimental and the numerical behaviour of the net under punching with different impact surfaces - left) $6 \mathrm{~mm}$ cable diameter, right) $8 \mathrm{~mm}$ cable diameter.

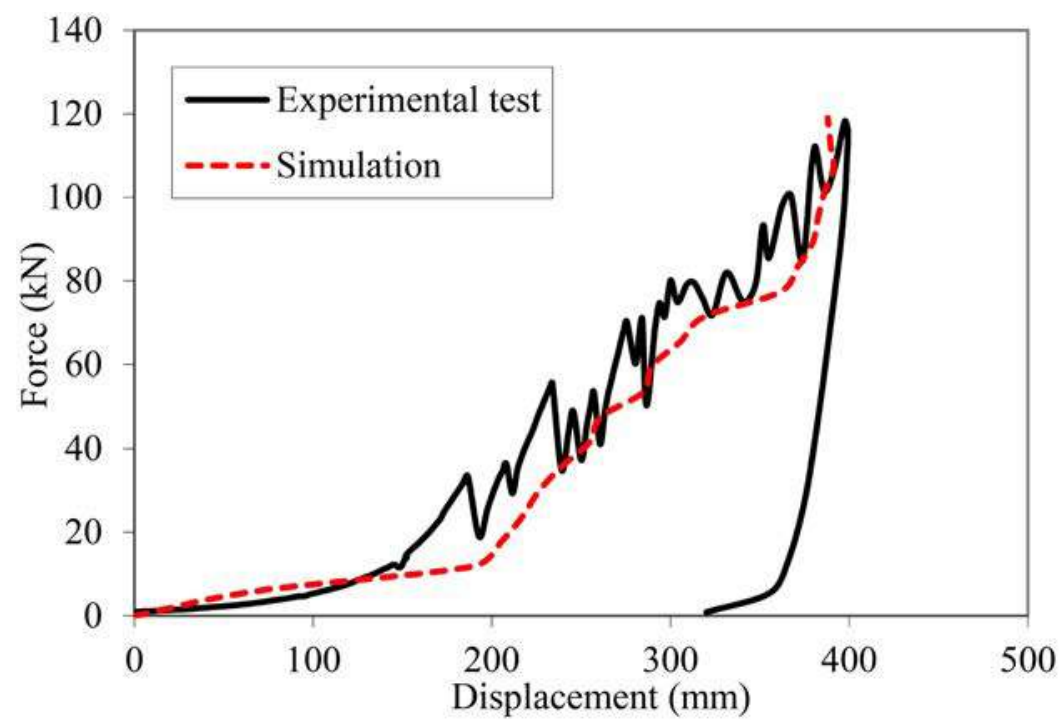

Figure 26. Simulation of the net punching test for the $6 \mathrm{~mm}$ net with fuse clips.

level of force then the force increases progressively with low amount of displacement. The increase of force continues till the failure of the 2 nd and 3rd clip. As the numerical model considers a perfect symmetry in geometry and in load transmission, the failure of the 2nd and 3rd clip are observed at the same time. After the failure of the 3 clips, the force increases till the failure of the cable. Figure 24 shows good global matching between the simulation and the experimental results. The incompatibility at the beginning of the curves is due to not taking into account the sliding observed at the interface fuse clip/cable.

\subsection{Numerical simulations of the net punching test with rigid and fuse clips}

The finite element model used to simulate the net with rigid clips (Figure 24) includes again the 'degraded beam' elements (same mesh density for each water drop cell as before). Rigid clips didn't fail during the punching test. Therefore, they are considered just as rigid connection between the beam elements. A couple of concentrated loads is applied within a circular area representative of the metallic spheres fixed on the head of the jack. The net is hinge connected at its four boundaries. The model calculation type is quasi-static incremental implicit, elastoplastic. Figure 25 shows the model and the net deformed shape. An adequate value for the reduction coefficient of the modulus of inertia was found again equal to 0.2 , confirming the efficiency of the study methodology. A comparison between the experimental and numerical behavioural curves for different configurations is shown in Figure 25. 
In the case of fuse clips, the numerical model is similar to the previous one but instead of a node-tonode junction at water drop cells intersection, the fuse clips are directly modelled by truss elements having an elastic-plastic behaviour. This material law represents a simplification of the clip's behaviour experimentally characterised. Again, in this case, where the fuse clips induce a non-smooth behaviour, Abaqus explicit analysis was privileged. The mechanical response of the net under loading is shown in Figure 19. The load increases until reaching a load level corresponding to the clip's failure. Finally, the global failure of the net occurs by the failure of the cable.

The numerical model didn't produce perfectly the experimental behaviour due to a lot of complex parameters involved during the experiment such as sliding and friction of cables inside the clips during the test and mainly dynamic effects each time a clip breaks, strength dissymmetry due to the real geometry of the net (the cells cannot have exactly the same dimensions), .... Overall, it can be considered that experimental and numerical results are in agreement as shown in Figure 26.

\section{Conclusion}

Various experimental and numerical studies have been conducted in order to understand well the behaviour of a specific cable-net used in the flexible barriers subjected to orthogonal solicitations.

A large experimental campaign addressing the characterization of cables, the behaviour of the constitutive cells of the net and the net itself is done in the case of quasi-static loading. These tests highlighted the non-linear behaviour obtained at different scales and permitted to evaluate the bearing capacity of the various components.

A numerical and analytical simulations were done for the cable when subjected to tensile and bending loading interaction. It was shown that a discretization with beams element considering a degradation of the bending stiffness, can reproduce well the behaviour observed experimentally. The same methodology, using implicit code and degraded beam element have showed a good correlation with experimental tests for the case of a representative number of cell's component submitted to tensile loading and finally to the net under puncturing test. All phases of the non-linear behaviour are well reproduced numerically in the case where the experimental behaviour corresponds to a smooth load deflection curve. In the cases characterized by local failure and stress redistribution inducing abrupt change in the net rigidity, as for the net with fuse clips, the correlation between simulation and the experiment was limited, and for this cases, explicit approach was mandatory due to the strong nonlinearities observed.

The next step will be to model the other different components of the barrier, including the energy dissipators, in the case of a rockfall dynamic impact. The calibrated numerical mechanical model, efficient for quasi-static loading, has to be evaluated in the case of a dynamic full-scale test of a whole flexible rockfall protection barrier.

\section{Disclosure statement}

No potential conflict of interest was reported by the authors.

\section{Funding}

This work was carried out under the support of NGE FONDATIONS company.

\section{References}

Anderheggen, E., Volkwein, A., \& Grassl, H. (2002). Numerical simulation of highly flexible rockfall protection systems. In: Proceedings of the fifth world congress on computational mechanics (WCCM V), Vienna, Austria. 2002.

Arndt, B., Ortiz, T., \& Turner, K. (2009). Colorado's full-scale field testing of rockfall attenuator systems, Transportation Research Circular E-C141., Transportation Research Board.

Bertolo, P., Oggeri, C., \& Peila, D. (2009). Full-scale testing of draped nets for rock fall protection. Canadian Geotechnical Journal, 46(3), 306-317. https://doi.org/10.1139/T08-126 
Bertrand, D., Trad, A., Limam, A., \& Silvani, C. (2012). Full-scale dynamic analysis of an innovative rockfall fence under impact using the discrete element method: from the local scale to the structure scale. Rock Mechanics and Rock Engineering., 45, 885-900.

Boulaud, R. (2020). Etudes et modélisations du comportement d'un écran de filet pare-blocs à différentes échelles. Université Paris-Est.

Cantarelli, G., Giani, G. P., Gottardi, G., \& Govoni, L. (2008). Modelling rockfall protection fences. Web Proc. of First World Landslide Forum. 662-667.

Castanon-Jano, L., Blanco-Fernandez, E., Castro-Fresno, D., \& Ferreño, D. (2018). Use of explicit FEM models for the structural and parametrical analysis of rockfall protection barriers. Engineering Structures, 166, 212-226. https://doi.org/10.1016/j.engstruct.2018.03.064

Castro-Fresno, D., Diaz, C., del, J. J., López, L. A., \& García Nieto, P. J. (2008). Evaluation of the resistance capacity of cable nets using the finite element method and experimental validation. Engineering Geology, 100(1-2), 1-10. https://doi.org/10.1016/j.enggeo.2008.02.007

Cazzani, A., Mongiovì, L., \& Frenez, T. (2002). Dynamic finite element analysis of interceptive devices for falling rocks. International Journal of Rock Mechanics and Mining Sciences, 39(3), 303-321. https://doi. org/10.1016/S1365-1609(02)00037-0

Coulibaly, J. (2017). Modélisation numérique discrète du comportement mécanique sous impact des structures d'écrans de filets pare-pierres. University Grenoble-Alpes. (in French).

Coulibaly, J. B., Chanut, M.-A., Lambert, S., \& Nicot, F. (2017). Non-linear discrete mechanical model of steel rings. Journal of Engineering Mechanics, 143(9), 04017087. https://doi.org/10.1061/(ASCE)EM.19437889.0001303

Coulibaly, J., Chanut, M.-A., Lambert., \& Nicot, F. (2019). Toward a generic computational approach for flexible rockfall barrier modelling. Rock Mech. Rock Eng.

Dugelas, L. (2020). Stratégies probabilistes appliquées a la modélisation numérique discrète: le cas des filets pare-pierres. University Grenoble-Alpes. (in French).

Dugelas, L., Coulibaly, J. B., Bourrier, F., Lambert, S., Chanut, M.-A., Olmedo, I., \& Nicot, F. (2019). Assessment of the predictive capabilities of discrete element models for flexible rockfall barriers. International Journal of Impact Engineering, 133, 103365. https://doi.org/10.1016/j.ijimpeng.2019.103365

EOTA (2018)., Falling rock protection kits, European Assessment Document - EAD 340059-00-0106. July.

Escallón, J., Wendeler, C., Chatzi, E., \& Bartelt, P. (2014). Parameter identification of rockfall protection barrier components through an inverse formulation. Engineering Structures, 77, 1-16. https://doi.org/10. 1016/j.engstruct.2014.07.019

ETAG 27. (2008). Guideline for European technical approval of falling rock protection kits.

Gerber, W. (2001). Guideline for the approval of rockfall protection kits. Swiss agency for the environment. Forests and Landscape (SAEFL), and Swiss Federal Research Institute WSL.

Grassl, H., Volkwein, A., Anderheggen, E., \& Ammann, J. (2002). Steel-net rockfall protectionExperimental and numerical simulation. WITTrans. Built Environ, 63, 11.

Hearn, G., Barrett, R. K., \& Henson, H. H. (1995). Development of effective rockfall barriers. Journal of Transportation Engineering, 121(6), 507-516. https://doi.org/10.1061/(ASCE)0733-947X(1995)121:6(507)

Moon, T., Oh, J., \& Mun, B. (2014). Practical design of rockfall catchfence at urban area from a numerical analysis approach. Engineering Geology, 172, 41-56. https://doi.org/10.1016/j.enggeo.2014.01.004

NF P95-308. (1996). French standard for the equipments of protection against rockfall: metallic-net barriers.

Nicot, F., Cambou, B., \& Mazzoleni, G. (2001). Design of rockfall restraining nets from a discrete element modelling. Rock Mechanics and Rock Engineering, 34(2), 99-118. https://doi.org/10.1007/s006030170017

Nicot, F., Cambou, B., \& Mazzoleni, G. (2001). From a constitutive modelling of metallic rings to the design of rockfall restraining nets. International Journal for Numerical and Analytical Methods in Geomechanics, 25(1), 49-70. https://doi.org/10.1002/1096-9853(200101)25:1<49::AID-NAG117>3.0.CO;2-N

Peila, D., Pelizza, S., \& Sassudelli, F. (1998). Evaluation of behaviour of rockfall restraining nets by full scale test. Rock Mechanics and Rock Engineering, 31(1), 1-24. https://doi.org/10.1007/s006030050006

Sasiharan, N., Muhunthan, B., Badger, T. C., Shu, S., \& Carradine, D. M. (2006). Numerical analysis of the performance of wire mesh and cable net rockfall protection systems. Engineering Geology, 88(1-2), 121-132. https://doi.org/10.1016/j.enggeo.2006.09.005

Trad, A., Limam, A., \& Robit, P. (2010). New energy dissipating device for rockfall protection barriers. Third Euro Mediterranean Symposium on Advances in Geomaterials and Structures. May 10-12. 
Volkwein, A. (2005). Numerical simulation of flexible rockfall protection systems [Paper presentation]. Proceedings of the ASCE International Conference on Computing in Civil Engineering, Cancun, Mexico, https://doi.org/10.1061/40794(179)122

Yu, Z., Liu, C., Guo, L., Zhao, L., \& Zhao, S. (2019). Nonlinear numerical modelling of the wire-ring net for flexible barriers. Shock and Vibration, 2019(3040213), 1-23. https://doi.org/10.1155/2019/3040213

Zhiwei, G., Hassan, A., \& Andrew, S. (2018). Experimental testing of low-energy rockfall catch fence meshes. Journal of Rock Mechanics and Geotechnical Engineering, 10(4), 798-804.

\section{Appendix A. The cable analytical model}

An analytical model is proposed for bending analysis of the cable. A cable with a length $L$ is pre-stressed by applying a load ' $P$ '. The goal is to study the influence of the pre-tension on the deformability of the cable. A load ' $T$ ' is applied perpendicularly to the cable. See Figure 8. The load ' $T$ ' induces a membrane effort $\mathrm{N}$ in the cable, this effort of tension generates an elongation $\delta$, where:

$\delta=\frac{N L}{E S}(a)$

$\mathrm{E}$ is the Young's modulus, $\mathrm{S}$ is the section and $\mathrm{N}$ is the axial normal force generated in the cable.

Alfa $(\alpha)$ is the angle between the deformed shape of the cable and the initial horizontal shape and delta $(\Delta)$ is the value of the displacement measured at the cable mid-length.

It can be found that: $\sin \alpha=\frac{\Delta}{(L+\delta) / 2}=2 \times \frac{\Delta}{L} \times \frac{1}{\left(1+\frac{N}{E S}\right)}$

The balance of forces gives: $2(N+P) \sin \alpha=T$

Thus: $4(N+P) \frac{\Delta}{L} \times \frac{1}{\left(1+\frac{N}{E S}\right)}=T(c)$

The cinematic equation gives: $\sqrt{\Delta^{2}+\left(\frac{L}{2}\right)^{2}}=\frac{L+\delta}{2}$

By simplification: $\Delta^{2}=\frac{L \delta}{2}+\left(\frac{\delta}{2}\right)^{2},\left(\frac{\delta}{2}\right)^{2}$ can be neglected comparing to $\frac{\delta}{2}$.

Then: $\Delta^{2}=\frac{L \delta}{2}$

Replacing in (a): $\frac{N}{E S}=\frac{\delta}{L}=2\left(\frac{\Delta}{L}\right)^{2}$

Replacing in (c): $4(N+P) \frac{\Delta}{L} \times \frac{1}{\left(1+2\left(\frac{\Delta}{L}\right)^{2}\right)}=T$

Or $: 4\left(2 E S\left(\frac{\Delta}{L}\right)^{2}+P\right) \frac{\Delta}{L} \times \frac{1}{\left(1+\frac{2}{2}\left(\frac{\Delta}{L}\right)^{2}\right)}=T$

Knowing that $\frac{\Delta}{L}<1$ and $\left(\frac{\Delta}{L}\right)^{\frac{2}{2}} \ll 1$, the equation can be simplified to: $4\left(2 E S\left(\frac{\Delta}{L}\right)^{2}+P\right) \frac{\Delta}{L}=T$

Then: $8\left(\frac{\Delta}{L}\right)^{3}+4 \frac{P}{E S} \frac{\Delta}{L}=\frac{T}{E S}$

This third-degree polynomial equation represents the behaviour of the cable under tensile and bending load. 